\title{
Optimising the process parameters of selective laser melting for the fabrication of Ti6Al4V alloy
}

\begin{tabular}{|r|l|}
\hline Journal: & Rapid Prototyping Journal \\
\hline Manuscript ID & RPJ-03-2016-0045.R3 \\
\hline Manuscript Type: & Original Article \\
\hline Keywords: & $\begin{array}{l}\text { Layered manufacturing, Optimization, Production processes, Surface } \\
\text { roughness, Ti-6A1-4V }\end{array}$ \\
\hline \multicolumn{2}{|c}{} \\
\hline
\end{tabular}

\section{SCHOLARONE $^{\text {m }}$ \\ Manuscripts}




\title{
Optimising the process parameters of selective laser melting for the fabrication of Ti6Al4V alloy
}

\begin{abstract}
Purpose- Surface roughness is an important evaluation index for industrial components and it strongly depends on the processing parameters for selective laser molten Ti6Al4V parts. This paper aims to obtain an optimum SLM parameter set to improve the surface roughness of Ti6Al4V samples. Design/methodology/approach- A response surface methodology (RSM) based approach is proposed to improve the surface quality of selective laser molten Ti6Al4V parts and understand the relationship between the selective laser melting (SLM) process parameters and the surface roughness. The main SLM parameters (i.e. laser power, scan speed and hatch spacing) are optimised and Ti6Al4V parts are manufactured by the SLM technology with no post processes.
\end{abstract}

Findings- Optimum process parameters were obtained using the RSM method to minimise the roughness of the top and vertical side surfaces. Obtained parameter sets were evaluated based on their productivity and surface quality performance. The validation tests have been performed and the results verified the effectivity of the proposed technique. It was also shown that the top and vertical sides must be handled together to obtain better top surface quality.

Practical implications- The obtained optimum SLM parameter set can be used in the manufacturing of Ti6Al4V components with high surface roughness requirement.

Originality/value- RSM is used to analyse and determine the optimal combination of SLM parameters with the aim of improving the surface roughness quality of Ti6Al4V components, for the first time in the literature. Also, this is the first study which aims to simultaneously optimise the surface quality of top and vertical sides of titanium alloys.

Keywords: selective laser melting; Ti6Al4V; response surface methodology; design of experiment; parameter optimisation

\section{Introduction}

Additive manufacturing (AM) was defined by the American Society for Testing and Materials F42 technical committee as the "process of joining materials to make objects from three-dimensional (3D) model data, usually layer upon layer, as opposed to subtractive manufacturing methodologies" (ASTM-F2792, 2010). It is the general term for a group of advanced manufacturing technologies, such as fused deposition modelling, stereolithography, laminated objective manufacturing, selective laser sintering, selective laser melting (SLM), electron beam melting and laser engineered net shaping (Khan and Dickens, 2010, Guo and Leu, 2013). Amongst the available AM processes, SLM enables the fabrication of final industrial parts directly from metal powders (Garg et al., 2014). During the SLM process, thin 
powder layers with a thickness of usually between $20 \mu \mathrm{m}$ and $60 \mu \mathrm{m}$ are spread on a metallic base plate and the cross-sections of the sliced computer-aided design file are scanned subsequently using a computer-controlled fibre laser beam. The metal powder materials in the cross-sections are melted and consolidated on the base plate or the produced part and this process continues layer-by-layer until the part is produced completely. The SLM process is conducted automatically and there is no need for the intervention of a technician. The manual work is required for pre-processes and post-processes (such as the preparation of the sliced file, the levelling of the building platform and removing the component from the base plate) and very small (Rickenbacher et al., 2013). Compared with conventional manufacturing processes, SLM offers a wide range of advantages, such as manufacturing components with complex geometry, reducing the time-to-market and maximising the material utilisation rate (Thijs et al., 2010).

Ti6Al4V was developed in the early 1950s for aerospace applications and now used extensively as the most common titanium alloy. Nowadays, Ti6Al4V alloys have been used in aerospace, medical instruments, biomedical implants, military and other highly stressed components (Yadroitsev et al., 2014, Ezugwu and Wang, 1997). The popularity of Ti6Al4V alloy is primarily owing to its wide range of advantages, such as lightness, high durability, excellent biocompatibility, high corrosion resistance and the ability to withstand extreme temperatures. However, machining bulk Ti6Al4V into components is difficult owing to its high strength and toughness. Additionally, it is easy for the titanium alloy to react with oxygen, nitrogen, hydrogen and carbon in thermal processes (Song et al., 2012). Therefore, excellent tools and process conditions are required to manufacture Ti6Al4V components using traditional manufacturing technologies.

Thanks to its special processing technology, SLM shows great advantage in manufacturing metal components from all kinds of materials, especially Ti6Al4V. However, the process parameters of SLM have a large influence on the final component property. Rehme and Emmelmann (2005) estimated that there are over 130 parameters that may affect the SLM process and about 13 of them are crucial in terms of the properties of the produced components. These crucial parameters include the diameter of the laser beam, laser power, scanning speed, hatch spacing, scanning strategy, layer thickness and oxygen concentration during the processing (Ferrar et al., 2012). Consequently, it is essential to investigate the optimal combination of processing parameters in order to fabricate high-surface quality metal components. Among these parameters, laser power, scanning speed and hatch spacing are the 
main processing factors that have been investigated in the majority of the research about parameter optimisation. Therefore, these three parameters were considered in the present study.

As a unique contribution to knowledge, this work verifies that the response surface methodology (RSM) method is a powerful technique for optimising the process parameters to improve the surface roughness of selective laser molten Ti6Al4V components. This work studies the influence of SLM process parameters (namely, laser power, scanning speed and hatch spacing) on the top and side surface roughness of Ti6Al4V for the first time in the literature. Moreover, RSM is used to analyse and determine the optimal combination of SLM parameters with the aim of improving the surface roughness quality of Ti6Al4V components, for the first time in the literature. The optimised parameter set was verified through validation experiments by manufacturing Ti6Al4V samples using the determined parameters.

A review of the literature on the fabrication of Ti6Al4V components and optimisation of SLM parameters is presented in Section 2. Information about the experiments carried out and the tests conducted for the aim of measuring the surface roughness is given in Section 3. The controlled SLM parameters are analysed and optimised through RSM and the results of the validation tests are reported in Section 4. The discussion about the optimised parameters and validation result is present in Section 5. The research is concluded in Section 6 and some possible implications of the research are expressed followed by the future work directions.

\section{Literature review}

The majority of the studies in the selective laser molten titanium domain to date have focused on the mechanical properties and microstructure of titanium and its alloy components (see for example Attar et al. (2014) for pure Titanium, Leordean et al. (2015) for Ti6Al7Nb, Liu et al. (2015) for Ti-24Nb-4Zr-8Sn and Wang et al. (2015) and Yadroitsev et al. (2014) for Ti6A14V). As the most commonly used titanium alloy, SLM-produced Ti6Al4V has been studied in terms of various aspects, such as materials, geometrical design, parameter optimisation, post-processing and industrial application. Vrancken et al. (2013) studied the influence of the properties of nine different materials (including Ti6Al4V) on residual stress. Liu et al. (2011) investigated the effect of particle size distribution on the mechanical properties of SLM-processed components, namely tensile strength and surface finish quality. Thijs et al. (2010) studied the development of the microstructure of the Ti6Al4V alloy and the influence of the scanning parameters and the scanning strategy on the microstructure. 
Vrancken et al. (2012) investigated the effect of several heat treatments on the microstructure and mechanical properties of Ti6Al4V. Thanks to the extensive research ranging from raw materials to final applications and the inherent advantages, Ti6Al4V has become the most successful material in the production and application based on SLM technology.

Owing to the great influence of SLM parameter set on the final component quality, the optimisation of SLM process parameters has vital importance for the quality of final product. The aim of the parameter optimisation is to identify and design the settings of process parameters that meet the requirements of defined product properties. Several optimisation methods have been used to design the SLM parameter sets. One common method is as follows:

- Single track scans or a series of bulk samples were carried out with different process parameters in order to define a process window for the processed material under the designated conditions.

- The process parameters, such as scanning speed, laser power and hatch spacing, are analysed according to the results from the previous step.

- The best parameter combination is determined through a large quantity of experiments and tests.

Kempen et al. (2011) optimised the process parameters to achieve full density, good surface quality and high productivity AlSi10Mg components using the above-mentioned method. It is obvious that this method is time-consuming and expensive owing to the large number of experiments and tests.

Finite element analysis (FEA) has been used to estimate the optimal SLM process parameters. For example, Song et al. (2012) optimised the laser scan rate for selective laser molten Ti6Al4V parts through simulating the temperature distribution. However, almost all of such studies focused on the analysis of a single scan or one layer as FEA is quite a time consuming method for this aim.

The Taguchi method and RSM are two other techniques that can be used for optimising the performance characteristics of a process or component. Sun et al. (2013) studied the effect of SLM process parameters on the density of produced samples using the Taguchi method. Carter et al. (2015) optimised the SLM process parameters for CMSX486 using RSM in order to produce consolidated components. Read et al. (2015) investigated the influence of SLM process parameters for fabricating AlSi10Mg using the RSM method. 
Few studies investigated the effects of the SLM parameters on surface roughness. Mumtaz and Hopkinson (2009) investigated the effects of SLM laser process parameters on the top surface and side surface roughness of Inconel 625 using the full factorial design. Calignano et al. (2012) studied the effect of SLM input parameters, namely laser power, scan speed and hatching distance, on the upper surface roughness of aluminum samples. The Taguchi method was used to select the process parameters in the same study. As seen from this literature review, it is clear that there has been no research using RSM to optimise the SLM parameters for fabricating Ti6A14V components. Therefore, this study aims to fill this gap by optimising the three important SLM parameters (i.e., laser power, scan speed and hatch spacing) using RSM to produce Ti6Al4V parts with improved top and side surface quality.

\section{Experiments and roughness tests}

The SLM experiments were carried out using the commercial EOSINT M280 (EOS GmbH Electro Optical Systems, Germany), which mainly consists of a continuous wave fibre laser with a wavelength of $1070 \mathrm{~nm}$. The specifications and parameters of the machine are shown in Table 1. Owing to the high reactivity of Ti6Al4V with oxygen, nitrogen, carbon and hydrogen, the SLM process was conducted in an enclosed argon environment with an oxygen content less than $0.1 \%$ (Van Bael et al., 2011). During the process, the scanning direction was rotated between each layer by a certain degree of $67^{\circ}$ (Kimura and Nakamoto, 2016) in order to realise identical mechanical properties in the horizontal direction.

Table 1. Machine specifications and parameters for Ti6Al4V

The material used in this study is commercially available as Ti6Al4V. According to the material supplier (EOS GmbH - Electro Optical Systems, Germany), the chemical composition of the titanium alloy is as follows (weight-wt.), Al: 5.5-6.75\%, V: $3.5-4.5 \%$, Ti: balanced. The average particle size and the particle size distribution were measured using a Mastersizer 2000 Laser Particle Analyser. The 10th, 50th and 90th percentiles of sieve diameter weighted by volume were $D_{10}=21.79 \mu \mathrm{m}, D_{50}=33.77 \mu \mathrm{m}, D_{90}=44.65 \mu \mathrm{m}$. Figure 1 shows the morphology of the Ti6Al4V powder. As seen from the figure, most of the particles have high sphericity and a smooth surface, so are suitable for the SLM process.

Figure 1. Morphology of Ti6Al4V powder 
After removing the processed specimens from the building platform using a wire electrical discharge machining process, adhering powders were cleaned with compressed air. The surface roughness tests were performed using an Olympus LEXT OLS4000 laser scanning confocal microscope. The top (X-Y, i.e., the laser melting layer plane) and side (X-Z, i.e., the building direction plane) surface roughness were investigated. Surface roughness was measured by the XYZ rapid scanning method; the measure scope was $2583 \mu \mathrm{m} \times 2582 \mu \mathrm{m}$; six scanning lines were distributed randomly (three in horizontal and three in vertical) in order to get more accurate results, as shown in Figure 2. The final roughness result is the mean value of the six test results. In the validation process, two spots on both top and side surface of the part were selected and six scanning lines were also distributed to measure the surface roughness in order to get more accurate test results.

Figure 2. Measure lines of surface roughness

\section{RSM and parameter optimisation}

RSM is a collection of mathematical and statistical techniques used for modelling of processes in which several input parameters (called factors) influence the output (called response) (Montgomery, 2001). The objective is to determine the optimal combination of factors that optimise the response. RSM was proposed by Box and Wilson (1951) and has been used widely as it is extremely useful to approximate a response function to experimental data, where the data cannot be described by linear functions. It simultaneously tests numerous factors in a limited number of experiments and thus consumes less time and effort in comparison with trial-and-error techniques, which test all possible combinations of parameters experimentally one-by-one. Furthermore, RSM gives the mathematical formulation of the process, which shows the relationships between the factors and responses, which also includes the interactions between the factors. This is the advantage of RSM over other design of experiments techniques, including the Taguchi method. Also, more accurate parameter values can be obtained by RSM as it has the capability to obtain optimal factors between the defined factor levels (Kucukkoc et al., 2013, Kucukkoc and Zhang, 2015). That is why RSM has been applied for the optimisation of SLM process parameters for fabricating Ti6Al4V with improved surface quality.

The general second-order polynomial response surface model (full quadratic model) used for the experimental design is given in Equation (1) (Yalcinkaya and Bayhan, 2009). 


$$
Y_{u}=\beta_{0}+\sum_{i=1}^{n} \beta_{i} X_{i u}+\sum_{i=1}^{n} \beta_{i i} X_{i u}^{2}+\sum_{i<j}^{n} \beta_{i j} X_{i u} X_{j u}+e_{u}
$$

where $Y_{u}$ is the corresponding response and $\beta_{0}, \beta_{i}, \beta_{i i}$ and $\beta_{i j}$ represent the regression coefficients. The terms $X_{i u}$ and $X_{j u}$ are coded values of the $i^{\text {th }}$ and $j^{\text {th }}$ input parameters $(i<j)$, respectively, and $e_{u}$ is the residual experimental error.

\subsection{Experimental design}

As explained in Section 1, three parameters were selected for the optimisation of SLM process. These parameters are laser power (LP), scan speed (SS) and hatch spacing (HS), for which factor levels are presented in Table 2. The factor levels have been determined by considering similar studies on SLM process in the literature (e.g., see Song et al. (2012) and Carter et al. (2015)) and the experience of the authors in this domain.

Table 2. Levels and values of SLM processing parameters

A well-known statistical software package, Minitab 16, was used to create the experimental design matrix and analyse the results. The experimental design matrix obtained for three parameters and three factor levels is presented in Table 3, where the factor values are given in un-coded units. The experiments were conducted in a randomised order to minimise the error. As seen from the table, 20 experiments were performed for this analysis. All 20 samples, each one is measured $8 \mathrm{~mm}$ in depth, $8 \mathrm{~mm}$ in width and $5 \mathrm{~mm}$ in height, were produced on the same Ti-based build plate at the same time (see Figure 3). During the manufacturing process, the machine was able to change its parameter setting for each sample based on the design of experiment created. Afterwards, the top surface roughness (TSR) and side surface roughness (SSR) values of each specimen were checked, as explained in Section 3. The responses (TSR and SSR) are reported in Table 3 for each experiment. The fitted regression models with the fitness value coefficients are formulated in the next subsection.

Table 3. The experimental design matrix and results

Figure 3. Specimens

\subsection{Parameter optimisation}


Minitab 16 was used to find the coefficients matrix and establish the regression models for predicting the responses (TSR and SSR). The RSM-based mathematical models, which represent the relation between the factors (LP, SS and HS) and responses (TSR and SSR), are given in un-coded units in Equation 2. The residual plots are also provided in the Appendices.

$$
\begin{gathered}
\text { TSR }=-57.98+1.54 * L P-0.12 * S S-228.35 * H S-1351.5 * H S^{2}+2.03 * L P * H S \\
+0.24 * S S * H S \\
S S R=-29.38-1.25 * L P+0.24 * S S+612.92 * H S+0.01 * L P^{2}+6170.68 * H S^{2} \\
\quad-8.19 * L P * H S-0.43 * S S * H S
\end{gathered}
$$

A two-stage approach was adopted for parameter optimisation. In the first stage, the aim was to minimise the TSR value only while both TSR and SSR values were aimed to be optimised with the same importance in the second stage. The optimal un-coded parameter setting for the first stage (referred to as OPS1) was obtained as $L P=150 \mathrm{~W}, S S=1080 \mathrm{~mm} / \mathrm{s}$ and $H S=0.08 \mathrm{~mm}$ with a composite desirability of $d=0.97$. The optimisation plot is given in Figure 4. In the second stage, the optimal un-coded parameter setting (referred to as OPS2) was obtained as $L P=150 \mathrm{~W}, S S=950 \mathrm{~mm} / \mathrm{s}$ and $H S=0.08 \mathrm{~mm}$ with a composite desirability of $d=0.85$. Figure 5 presents the parameter optimisation plot in this stage. The optimal values of the parameters (OPS1 and OPS2) are presented in Table 4 for both stages.

Figure 4. Optimisation plot to minimise TSR

Table 4. Optimised parameter sets for different responses

Figure 5. Optimisation plot to minimise TSR and SSR

\subsection{Validation tests}

For validation purposes, three specimens were produced using each optimised parameter set and the TSR and SSR values of each specimen were measured. The mean TSR and SSR values of each parameter set are reported in Table 5. Furthermore, three specimens were produced using the default parameters of the SLM machine and the results are reported in the 'Default' column in Table 5 so that the performance of the proposed RSM based approach can be compared to the parameters provided by the manufacturer of the machine. Please note that the default parameters of the SLM machine for Ti6Al4V have been pre-set by the machine supplier and are secret. 
Table 5. Roughness comparison of optimised and default parameters

As reported in Table 5, the TSR of Ra $13.949 \mu \mathrm{m}$ was obtained when OPS1 was used, which is better than the TSR of Ra $17.182 \mu \mathrm{m}$ found when the default parameter set was used. However, the SSR of Ra $49.173 \mu \mathrm{m}$ obtained when OPS1 was used is larger than the SSR of $\mathrm{Ra} 40.039 \mu \mathrm{m}$ when the default parameter set was used. These results verify the effectivity of OPS1 as it aims to optimise TSR only (not SSR). OPS2 yields a better TSR value than that obtained with the default parameters. Furthermore, when the OPS2 was used, the TSR and SSR were obtained as Ra $11.510 \mu \mathrm{m}$ and $\mathrm{Ra} 40.314 \mu \mathrm{m}$, respectively, which are better than the results obtained when OPS1 was used.

\section{Discussion}

A scanning electron microscope (SEM) analysis has been carried out for the validation samples which do not have any post surface treatment. Figure 6 and Figure 7 show the profile of top and side surface of the samples in the condition of OPS1, OPS2 and default parameter set. As shown in Figure 6, it is obvious that the surface smoothness shows improvement from default parameter set to OPS1 to OPS2, which verifies the TSR results presented in Table 5.

Figure 6. Top surface microtopography of samples in the conditions: (a-b) OPS1, (c-d) OPS2 and (e-f) default parameter set

Figure 7. Side surface microtopography of samples in the conditions: (a-b) OPS1, (c-d) OPS2 and (ef) default parameter set

During the laser melting, powder particles on the edge borders can not be fully melted. Therefore, many particles stick to the side surfaces, especially the vertical side surface, which is the main reason yielding unsatisfactory surface roughness (Strano et al., 2013). As shown in Figure 7, the adhered particles show nearly no difference between OPS2 and default parameter set conditions. However, OPS1 has slightly more adhered particles than OPS2 and default parameter set, supporting the SSR results presented in Table 5.

The results of the SEM analysis (and the validation tests presented in Section 4.3) indicate that the OPS2 is the most effective parameter combination for both TSR and SSR. Therefore, 
the optimal process parameters for both surfaces are laser power $(L P)=150 \mathrm{~W}$, scanning speed $(S S)=950 \mathrm{~mm} / \mathrm{s}$ and hatch spacing $(H S)=0.08 \mathrm{~mm}$. This study indicates that both TSR and SSR should be optimised concurrently to have a better surface roughness value.

To measure the influence of the energy density involved in SLM process on the porosity of the fabricated parts, the density of each validation sample was measured by Archimedes method given in Equation (4) and presented in Table 6 (see the Density $\left(\mathrm{g} / \mathrm{cm}^{3}\right)$ column) The obtained density values have been proportioned to the theoretical density values (Sun et al., 2013) and reported in the percentage (\%) column.

$$
\rho=\frac{m_{1} \rho_{0}}{m_{1}-m_{2}}
$$

where, $\rho$ denotes the density of the sample; $m_{1}$ and $m_{2}$ are the sample's mass in air and in stilled water, respectively; $\rho_{0}\left(0.998 \mathrm{~g} / \mathrm{cm}^{3}\right)$ is the density of stilled water.

Table 6 . The density of validation samples

Using the parameter levels reported in Table 4, the energy density levels for OPS1 and OPS2 parameter sets are calculated as $58 \mathrm{~J} / \mathrm{cm}^{3}$ and $66 \mathrm{~J} / \mathrm{cm}^{3}$, respectively. Despite these different energy density levels, the density of the validation samples fabricated using OPS1, OPS2 and default parameter set are the same, $4.43 \mathrm{~g} / \mathrm{cm}^{3}$. This indicates that the change in the energy density between $58 \mathrm{~J} / \mathrm{cm}^{3}$ and $66 \mathrm{~J} / \mathrm{cm}^{3}$ has no effect on the density of the parts but on the roughness and productivity.

An evaluation of optimised parameter sets and default parameter set is presented in Table 7 in accordance with productivity and surface quality values. As reported in the table, OPS1 and OPS2 have medium and low productivity performances, respectively, since a higher scan speed means higher productivity. OPS1 provides a high-quality top surface and a mediumquality side surface. However, OPS2 provides the highest-quality top and side surfaces, although its productivity is low. Although the default parameter set is highly productive, the top surface quality obtained when the default parameter set is less than those obtained when OPS1 and OPS2 were used. This shows the advantage of the proposed parameters over default setting provided by the machine suppliers. Practitioners in industry can choose the 
best parameter set from this table based on their needs, considering the balance between surface quality and productivity of different industrial components. This is especially important to improve the surface roughness of the parts with complex internal structures, for which the traditional surface treatment methods are not practical to uniformly improve the surface quality.

Table 7. Application of parameter sets

\section{Conclusion and future work}

The surface quality of selective laser molten Ti6Al4V parts has been optimised through determining the optimum process parameters, namely laser power, scan speed and hatch spacing. A well-known design of experiment technique, RSM, has been used to analyse the relationship between the surface quality and process parameters.

Unlike the common tendency in the literature, this paper examined the effect of process parameters on surface roughness of Ti6Al4V parts produced using SLM technology in terms of two different objectives, namely top surface roughness and side surface roughness. This study indicated that both TSR and SSR should be optimised concurrently to obtain better top surface roughness values. Better surface quality was obtained in comparison with the default parameters provided by the machine supplier.

In terms of the potential applications of the study, the results presented here can be used in industry for manufacturing Ti6Al4V components with high surface quality requirements and complex internal structures. One limitation of the study is that the optimised parameter set shows low productivity owing to the low scan speed. More research is needed to overcome this issue. In addition, only the top and vertical side surface roughness were optimised in this study. However, there are many different angled surfaces in industrial components. Therefore, process parameter optimisation should be carried out for different angled surfaces in future work. More process parameters can be considered in the parameter optimisation process in order to obtain higher surface quality. 
Appendices

Figure A.1. Residual plot for TSR

Figure A.2. Residual plot for SSR

\section{References}

ASTM-F2792 2010. Standard terminology for additive manufacturing technologies.

ATTAR, H., CALIN, M., ZHANG, L. C., SCUDINO, S. \& ECKERT, J. 2014. Manufacture by selective laser melting and mechanical behavior of commercially pure titanium. Materials Science and Engineering: A, 593, 170-177.

BOX, G. E. P. \& WILSON, K. B. 1951. On the Experimental Attainment of Optimum Conditions. Journal of the Royal Statistical Society Series B-Statistical Methodology, 13, 1-45.

CALIGNANO, F., MANFREDI, D., AMBROSIO, E. P., IULIANO, L. \& FINO, P. 2012. Influence of process parameters on surface roughness of aluminum parts produced by DMLS. The International Journal of Advanced Manufacturing Technology, 67, 2743-2751.

CARTER, L. N., ESSA, K., ATTALLAH, M. M., CAMPBELL, R. I. \& CAMPBELL, R. I. 2015. Optimisation of Selective Laser Melting for a high temperature Ni superalloy. Rapid Prototyping Journal, 21.

EZUGWU, E. \& WANG, Z. 1997. Titanium alloys and their machinability-a review. Journal of materials processing technology, 68, 262-274.

FERRAR, B., MULLEN, L., JONES, E., STAMP, R. \& SUTCLIFFE, C. J. 2012. Gas flow effects on selective laser melting (SLM) manufacturing performance. Journal of Materials Processing Technology, 212, 355-364.

GARG, A., TAI, K. \& SAVALANI, M. M. 2014. Formulation of bead width model of an SLM prototype using modified multi-gene genetic programming approach. The International Journal of Advanced Manufacturing Technology, 73, 375-388.

GUO, N. \& LEU, M. C. 2013. Additive manufacturing: technology, applications and research needs. Frontiers of Mechanical Engineering, 8, 215-243.

KEMPEN, K., THIJS, L., YASA, E., BADROSSAMAY, M., VERHEECKE, W. \& KRUTH, J. Process optimization and microstructural analysis for selective laser melting of AlSi10Mg. Solid Freeform Fabrication Symposium, 2011. 484-495.

KHAN, M. \& DICKENS, P. 2010. Selective Laser Melting (SLM) of pure gold. Gold Bulletin, 43, 114-121.

KIMURA, T. \& NAKAMOTO, T. 2016. Microstructures and mechanical properties of A356 (AlSi7Mg0.3) aluminum alloy fabricated by selective laser melting. Materials \& Design, 89, 1294-1301.

KUCUKKOC, I., KARAOGLAN, A. D. \& YAMAN, R. 2013. Using response surface design to determine the optimal parameters of genetic algorithm and a case study. International Journal of Production Research, 51, 5039-5054, doi: http://dx.doi.org/10.1080/00207543.2013.784411.

KUCUKKOC, I. \& ZHANG, D. Z. 2015. Type-E parallel two-sided assembly line balancing problem: Mathematical model and ant colony optimisation based approach with optimised parameters. Computers and Industrial Engineering, 84, 56-69, doi: http://dx.doi.org/10.1016/i.cie.2014.12.037.

LEORDEAN, D., DUDESCU, C., MARCU, T., BERCE, P. \& BALC, N. 2015. Customized implants with specific properties, made by selective laser melting. Rapid Prototyping Journal, 21, 98-104.

LIU, B., WILDMAN, R., TUCK, C., ASHCROFT, I. \& HAGUE, R. Investigation the effect of particle size distribution on processing parameters optimisation in Selective Laser Melting process. International solid freeform fabrication symposium: an additive manufacturing conference. University of Texas at Austin, Austin, 2011. 227-238.

LIU, Y. J., LI, X. P., ZHANG, L. C. \& SERCOMBE, T. B. 2015. Processing and properties of topologically optimised biomedical Ti-24Nb-4Zr-8Sn scaffolds manufactured by selective laser melting. Materials Science and Engineering: A, 642, 268-278. 
MONTGOMERY, D. C. 2001. Design and Analysis of Experiments, 5th ed., New York, John Wiley.

MUMTAZ, K. \& HOPKINSON, N. 2009. Top surface and side roughness of Inconel 625 parts processed using selective laser melting. Rapid Prototyping Journal, 15, 96-103.

READ, N., WANG, W., ESSA, K. \& ATTALLAH, M. M. 2015. Selective laser melting of AlSi10Mg alloy: Process optimisation and mechanical properties development. Materials \& Design, 65, 417424.

REHME, O. \& EMMELMANN, C. Reproducibility for properties of selective laser melting products. Proceedings of the Third International WLT-Conference on Lasers in Manufacturing, Munich, 2005. 1-6.

RICKENBACHER, L., SPIERINGS, A. \& WEGENER, K. 2013. An integrated cost-model for selective laser melting (SLM). Rapid Prototyping Journal, 19, 208-214.

SONG, B., DONG, S., LIAO, H. \& CODDET, C. 2012. Process parameter selection for selective laser melting of Ti6Al4V based on temperature distribution simulation and experimental sintering. The International Journal of Advanced Manufacturing Technology, 61, 967-974.

STRANO, G., HAO, L., EVERSON, R. M. \& EVANS, K. E. 2013. Surface roughness analysis, modelling and prediction in selective laser melting. Journal of Materials Processing Technology, 213, 589-597.

SUN, J., YANG, Y. \& WANG, D. 2013. Parametric optimization of selective laser melting for forming Ti6Al4V samples by Taguchi method. Optics \& Laser Technology, 49, 118-124.

THIJS, L., VERHAEGHE, F., CRAEGHS, T., HUMBEECK, J. V. \& KRUTH, J.-P. 2010. A study of the microstructural evolution during selective laser melting of Ti-6Al-4V. Acta Materialia, 58, 3303-3312.

VAN BAEL, S., KERCKHOFS, G., MOESEN, M., PYKA, G., SCHROOTEN, J. \& KRUTH, J. P. 2011. Micro-CTbased improvement of geometrical and mechanical controllability of selective laser melted Ti6Al4V porous structures. Materials Science and Engineering: A, 528, 7423-7431.

VRANCKEN, B., THIJS, L., KRUTH, J.-P. \& VAN HUMBEECK, J. 2012. Heat treatment of Ti6AI4V produced by Selective Laser Melting: Microstructure and mechanical properties. Journal of Alloys and Compounds, 541, 177-185.

VRANCKEN, B., WAUTHLÉ, R., KRUTH, J.-P. \& VAN HUMBEECK, J. Study of the influence of material properties on residual stress in selective laser melting. Proceedings of the solid freeform fabrication symposium, 2013. 393.

WANG, Y., JIANG, J., QIAO, L., HU, D., LI, Z., LI, M. \& CHEN, Y. 2015. Study on biological corrosion and biocompatibility of TC4 alloy by selective laser melting. Journal of Chongqing University, 3.

YADROITSEV, I., KRAKHMALEV, P. \& YADROITSAVA, I. 2014. Selective laser melting of Ti6AI4V alloy for biomedical applications: Temperature monitoring and microstructural evolution. Journal of Alloys and Compounds, 583, 404-409.

YALCINKAYA, O. \& BAYHAN, G. M. 2009. Modelling and optimization of average travel time for a metro line by simulation and response surface methodology. European Journal of Operational Research, 196, 225-233. 


\section{Acknowledgment}

This research was supported by the National High Technology Research and Development Program of China (863 Program: 2015AA042501). 
Table 1. Machine specifications and parameters for Ti6Al4V

\begin{tabular}{ll}
\hline Property & Value \\
\hline Machine & EOS M280 \\
Platform dimension $(\mathrm{L} \times \mathrm{W} \times \mathrm{H})$ & $250 \times 250 \times 325(\mathrm{~mm})$ \\
Laser type & Fibre laser \\
Laser diameter & $100 \mu \mathrm{m}$ \\
Maximum laser power & $200 \mathrm{~W}$ \\
Maximum scan speed & $7 \mathrm{~m} / \mathrm{s}$ \\
Atmosphere & $\mathrm{Argon},<0.1 \%$ \\
Layer thickness & $30 \mu \mathrm{m}$ \\
Pre-substrate temperature & $35^{\circ} \mathrm{C}$ \\
\hline
\end{tabular}


Table 2. Levels and values of SLM processing parameters

\begin{tabular}{lcccc}
\hline \multirow{2}{*}{ Parameters } & \multirow{2}{*}{ Symbol } & \multicolumn{3}{c}{ Levels } \\
\cline { 3 - 5 } & & -1 & 0 & 1 \\
\hline Laser power $(\mathrm{W})$ & LP & 150 & 170 & 190 \\
Scan speed $(\mathrm{mm} / \mathrm{s})$ & $\mathrm{SS}$ & 950 & 1250 & 1550 \\
Hatch spacing $(\mathrm{mm})$ & HS & 0.08 & 0.1 & 0.12 \\
\hline
\end{tabular}


Table 3. The experimental design matrix and results

\begin{tabular}{cccccccc}
\hline \multirow{2}{*}{ Run Order } & \multirow{2}{*}{ Standard Order } & \multicolumn{2}{c}{ Factors (in un-coded units) } & & \multicolumn{2}{c}{ Responses } \\
\cline { 3 - 4 } \cline { 6 - 7 } & & LP $(\mathrm{W})$ & SS $(\mathrm{mm} / \mathrm{s})$ & HS $(\mathrm{mm})$ & & TSR $(\mu \mathrm{m})$ & SSR $(\mu \mathrm{m})$ \\
\hline 1 & 13 & 170 & 1250 & 0.08 & & 13.739 & 50.531 \\
2 & 10 & 190 & 1250 & 0.1 & & 17.337 & 49.226 \\
3 & 20 & 170 & 1250 & 0.1 & & 17.910 & 45.984 \\
4 & 19 & 170 & 1250 & 0.1 & & 21.366 & 41.465 \\
5 & 5 & 150 & 950 & 0.12 & & 11.093 & 44.133 \\
6 & 2 & 190 & 950 & 0.08 & & 12.977 & 42.386 \\
7 & 7 & 150 & 1550 & 0.12 & & 28.533 & 47.969 \\
8 & 8 & 190 & 1550 & 0.12 & & 30.979 & 29.713 \\
9 & 15 & 170 & 1250 & 0.1 & & 15.193 & 32.602 \\
10 & 16 & 170 & 1250 & 0.1 & & 18.197 & 38.817 \\
11 & 6 & 190 & 950 & 0.12 & & 19.917 & 45.537 \\
12 & 4 & 190 & 1550 & 0.08 & & 22.918 & 45.530 \\
13 & 11 & 170 & 950 & 0.1 & & 14.339 & 34.851 \\
14 & 18 & 170 & 1250 & 0.1 & & 17.549 & 40.206 \\
15 & 17 & 170 & 1250 & 0.1 & & 15.991 & 44.296 \\
16 & 9 & 150 & 1250 & 0.1 & & 13.859 & 36.204 \\
17 & 14 & 170 & 1250 & 0.12 & & 20.033 & 33.548 \\
18 & 3 & 150 & 1550 & 0.08 & & 19.020 & 41.986 \\
19 & 12 & 170 & 1550 & 0.1 & & 29.371 & 35.895 \\
20 & 1 & 150 & 950 & 0.08 & & 12.093 & 36.570 \\
\hline
\end{tabular}


Table 4. Optimised parameter sets for different responses

\begin{tabular}{lcccc}
\hline Parameter Set No & Response & LP (W) & SS (mm/s) & HS (mm) \\
\hline Optimised Parameter Set-1 (OPS1) & TSR & 150 & 1080 & 0.08 \\
Optimised Parameter Set-2 (OPS2) & TSR\&SSR & 150 & 950 & 0.08 \\
\hline
\end{tabular}


1

2

3

4

5

6

7

8

9

10

11

12

13

14

15

16

17

18

19

20

21

22

23

24

25

26

27

28

29

30

31

32

33

34

35

36

37

38

39

40

41

42

43

44

45

46

47

48

49

50

51

52

53

54

55

56

57

58

59

60

Table 5. Roughness comparison of optimised and default parameters

\begin{tabular}{cccc}
\hline Mean Values & OPS1 & OPS2 & Default \\
\hline TSR & 13.949 & 11.510 & 17.182 \\
SSR & 49.173 & 40.314 & 40.039 \\
\hline
\end{tabular}


Table 6 . The density of validation samples

\begin{tabular}{cccc}
\hline \multirow{2}{*}{ Parameter Set } & \multirow{2}{*}{ Theoretical Density $\left(\mathrm{g} / \mathrm{cm}^{3}\right)$} & \multicolumn{2}{c}{ Density } \\
\cline { 3 - 4 } & & $\left(\mathrm{g} / \mathrm{cm}^{3}\right)$ & $(\%)$ \\
\hline OPS1 & \multirow{3}{*}{4.44} & 4.43 & 99.8 \\
OPS2 & & 4.43 & 99.8 \\
Default & 4.43 & 99.8 \\
\hline
\end{tabular}

12

13

14

15

16

17

18

19

20

21

22

23

24

25

26

27

28

29

30

31

32

33

34

35

36

37

38

39

40

41

42

43

44

45

46

47

48

49

50

51

52

53

54

55

56

57

58

59

60 
1

2

3

4

5

6

7

8

9

10

11

12

13

14

15

16

17

18

19

20

21

22

23

24

25

26

27

28

29

30

31

32

33

34

35

36

37

38

39

40

41

42

43

44

45

46

47

48

49

50

51

52

53

54

55

56

57

58

59

60

Table 7. Application of parameter sets

\begin{tabular}{cccc}
\hline \multirow{2}{*}{ Parameter set } & Productivity & \multicolumn{2}{c}{ Surface quality } \\
\cline { 3 - 4 } & & Top & Side \\
\hline OPS1 & Medium & High & Medium \\
OPS2 & Low & High & High \\
Default & High & Low & High \\
\hline
\end{tabular}




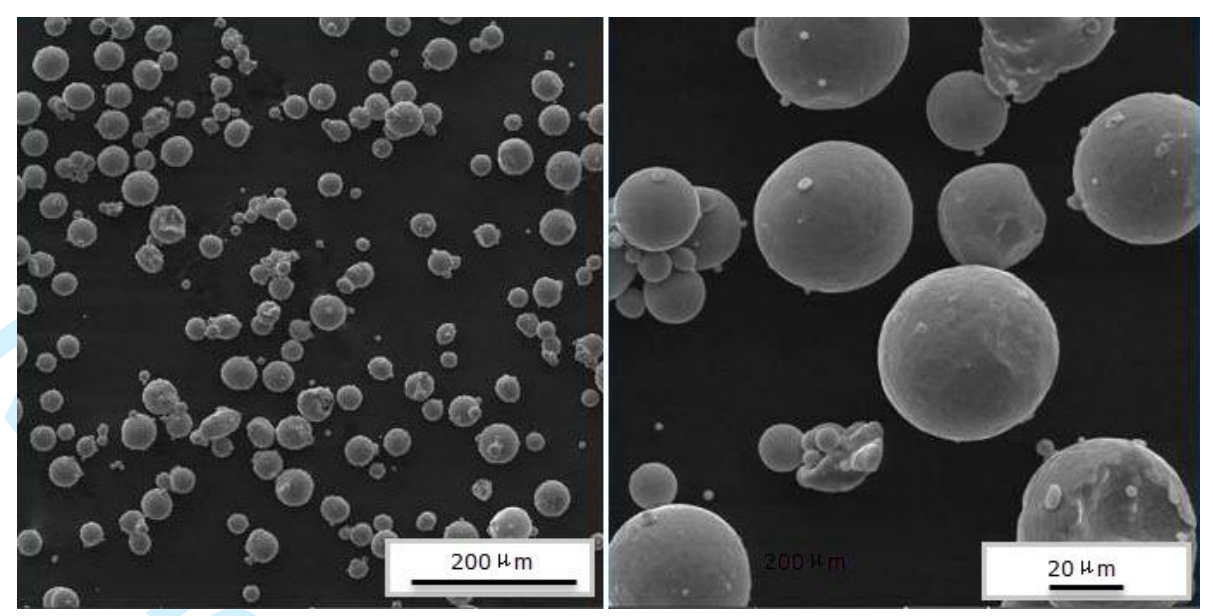

Figure 1. Morphology of Ti6Al4V powder 


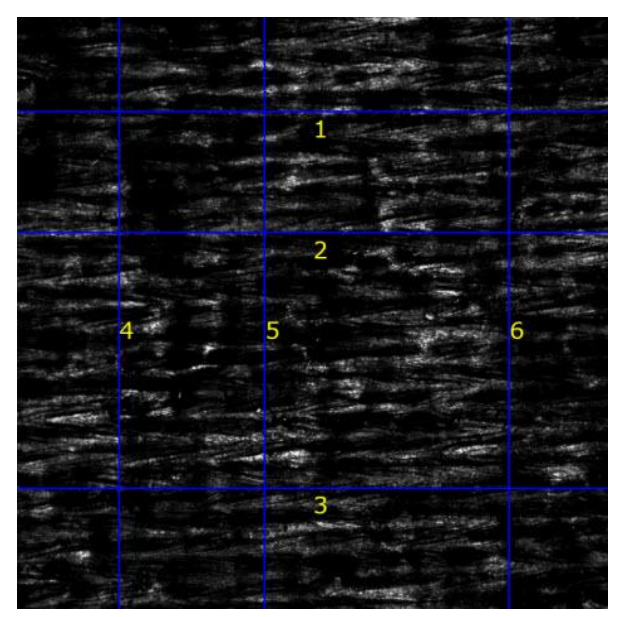

Figure 2. Measure lines of surface roughness 


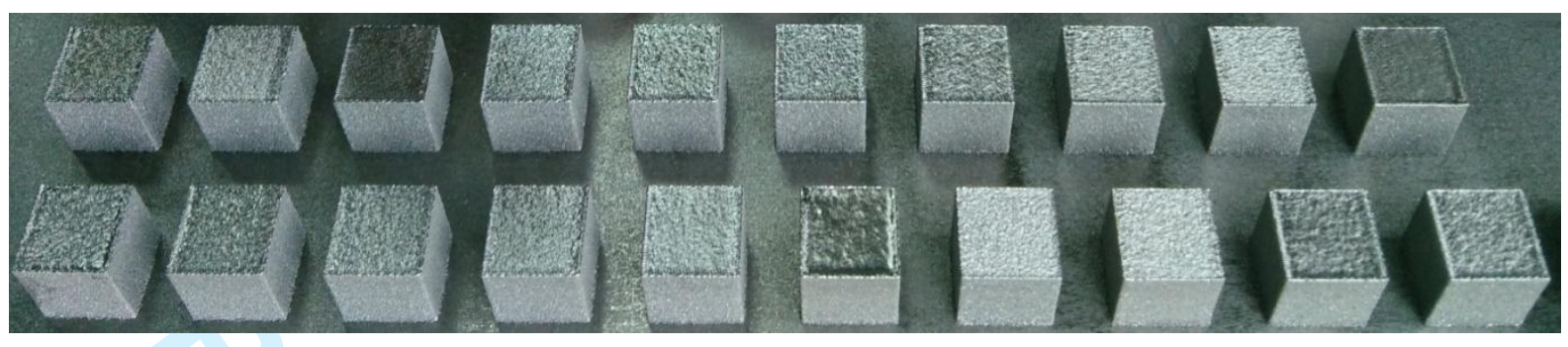

Figure 3. Specimens 


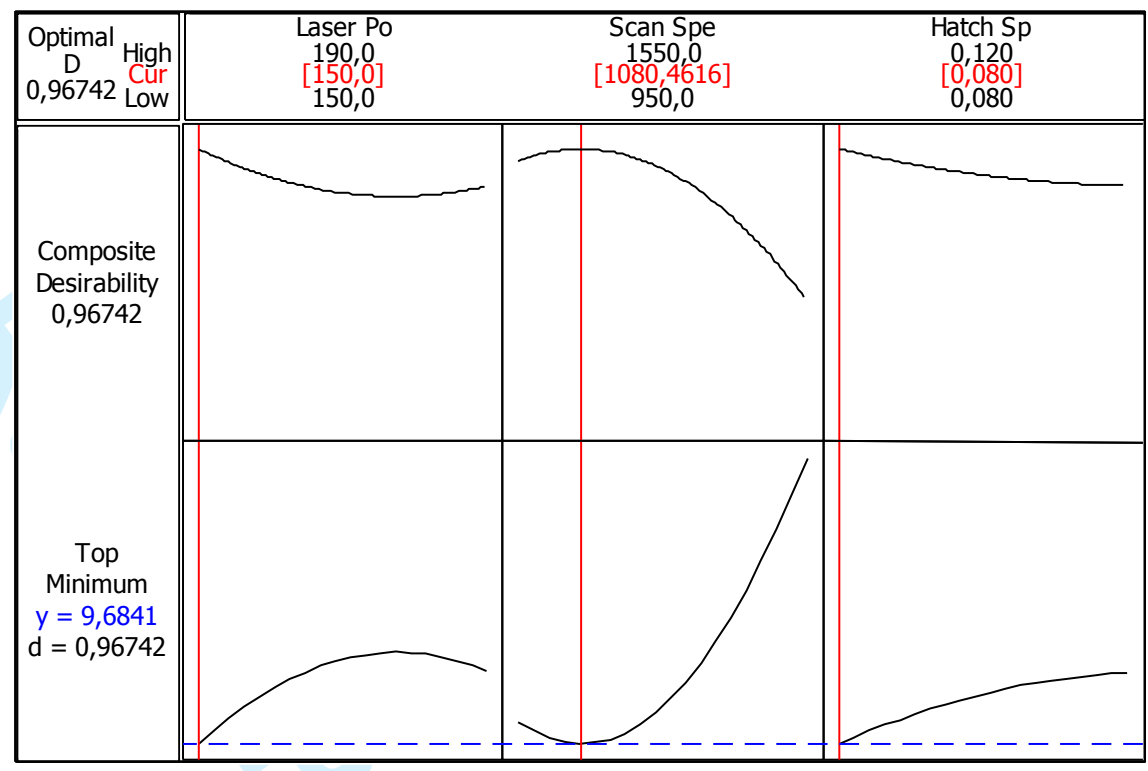

Figure 4. Optimisation plot to minimise TSR 


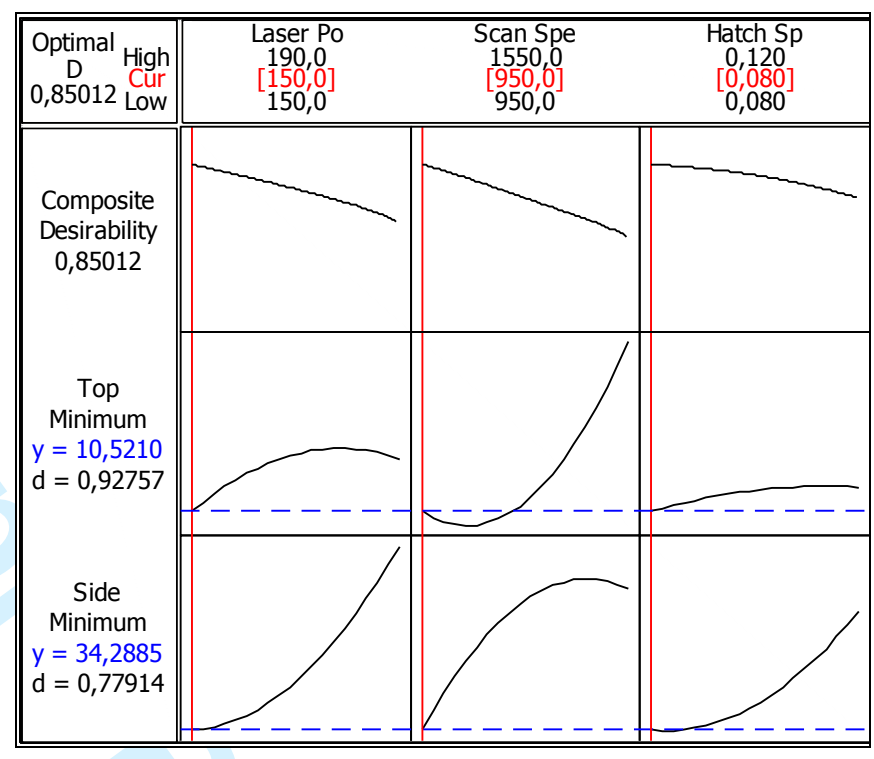

Figure 5. Optimisation plot to minimise TSR and SSR 
1

2

3

4

5

6
7

8

9

10

11

12

13

14

15

16

17

18

19

20

21

22

23

24

25

26

27

28

29

30

31

32

33

34

35

36

37

38

39

40

41

42

43

44

45

46

47

48

49

50

51

52

53

54

55

56

57

58

59

60
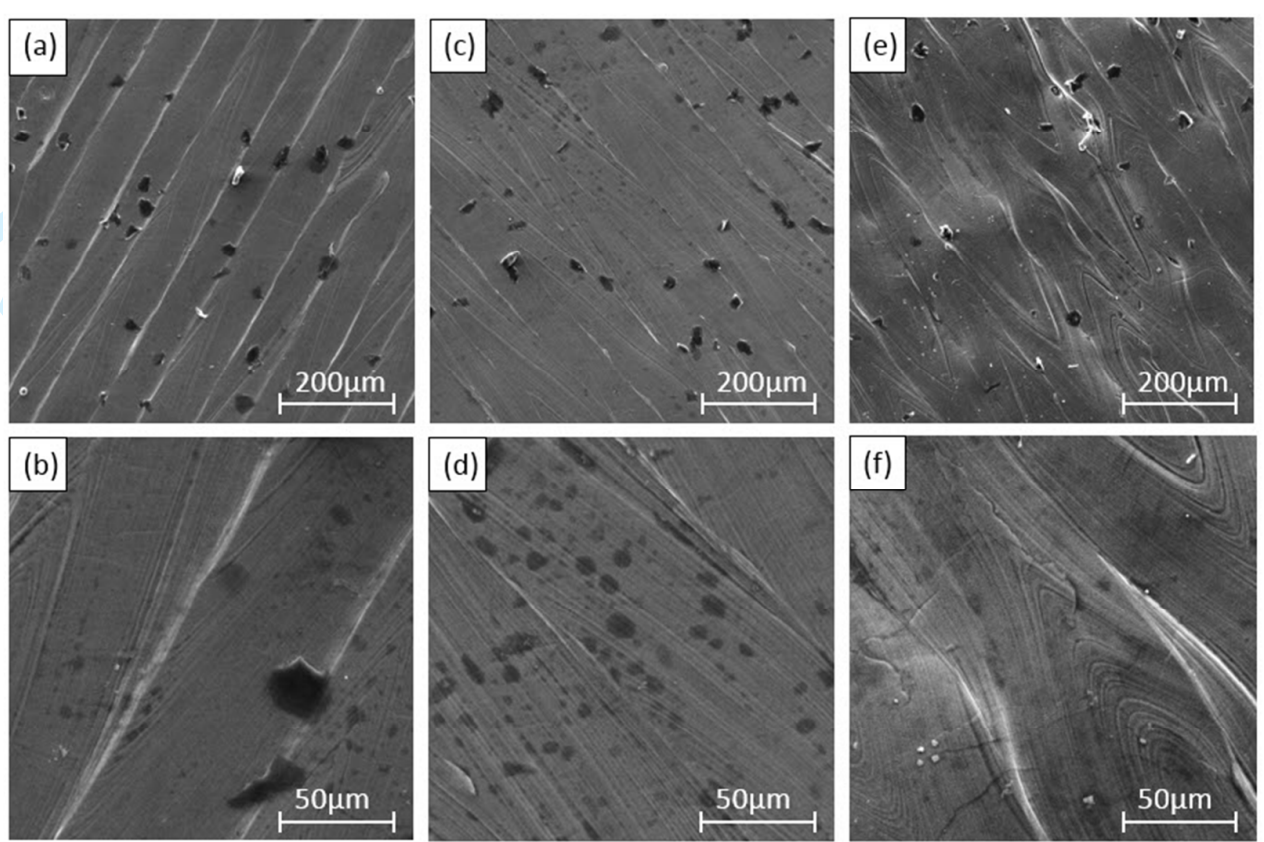

Figure 6. Top surface microtopography of samples in the conditions: (a-b) OPS1, (c-d) OPS2 and (e-f) default parameter set 

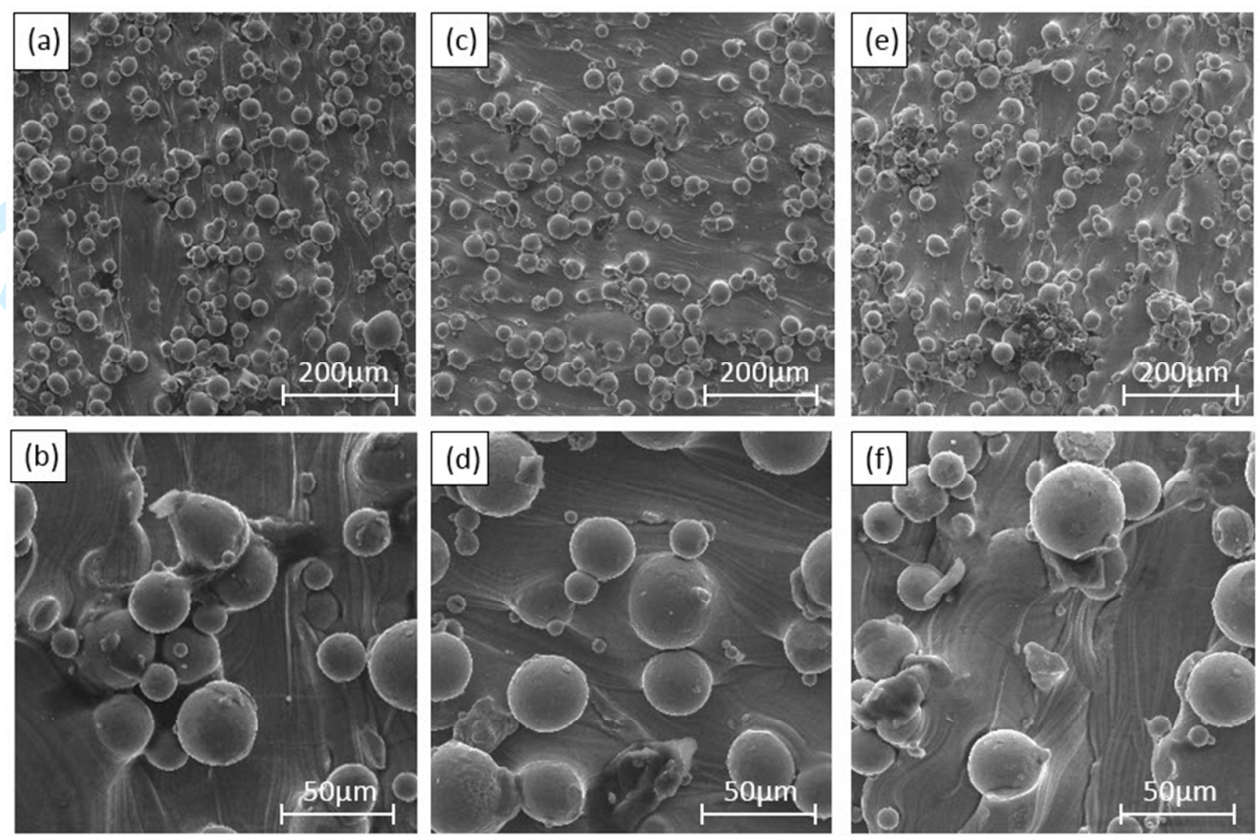

Figure 7. Side surface microtopography of samples in the conditions: (a-b) OPS1, (c-d) OPS2 and (ef) default parameter set 


\section{A. 1. Residual plot for TSR}

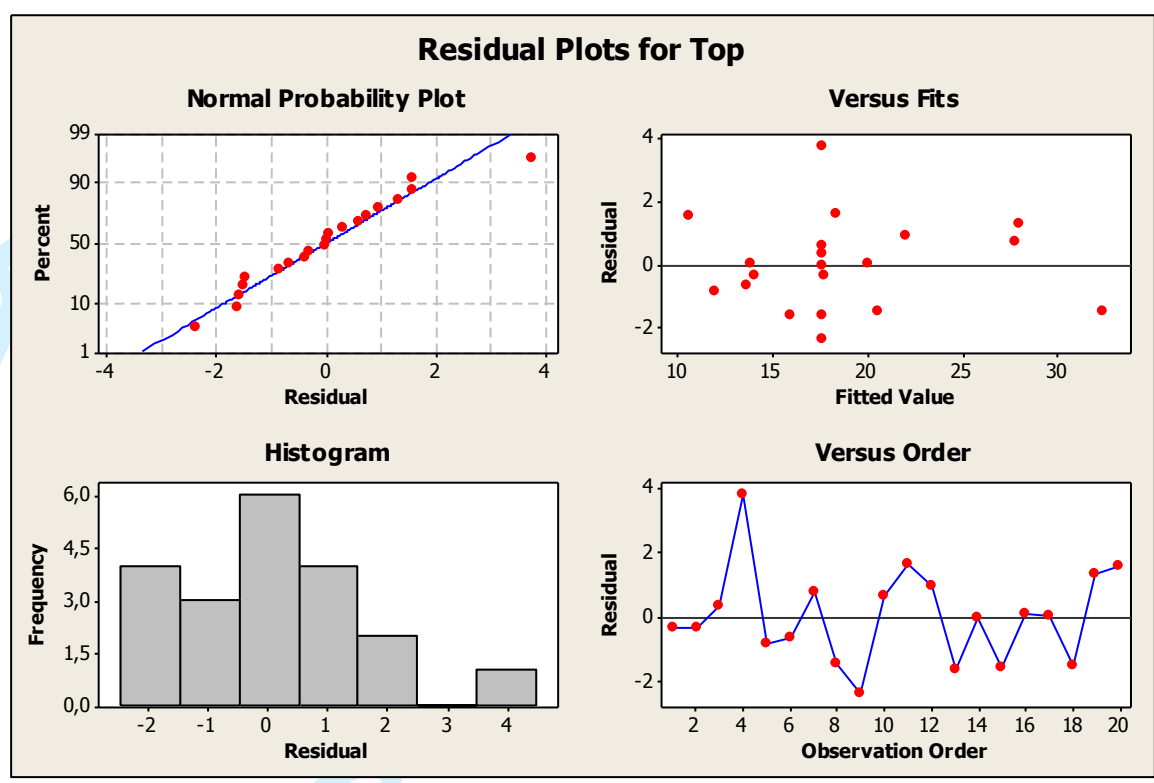




\section{A. 2. Residual plot for SSR}

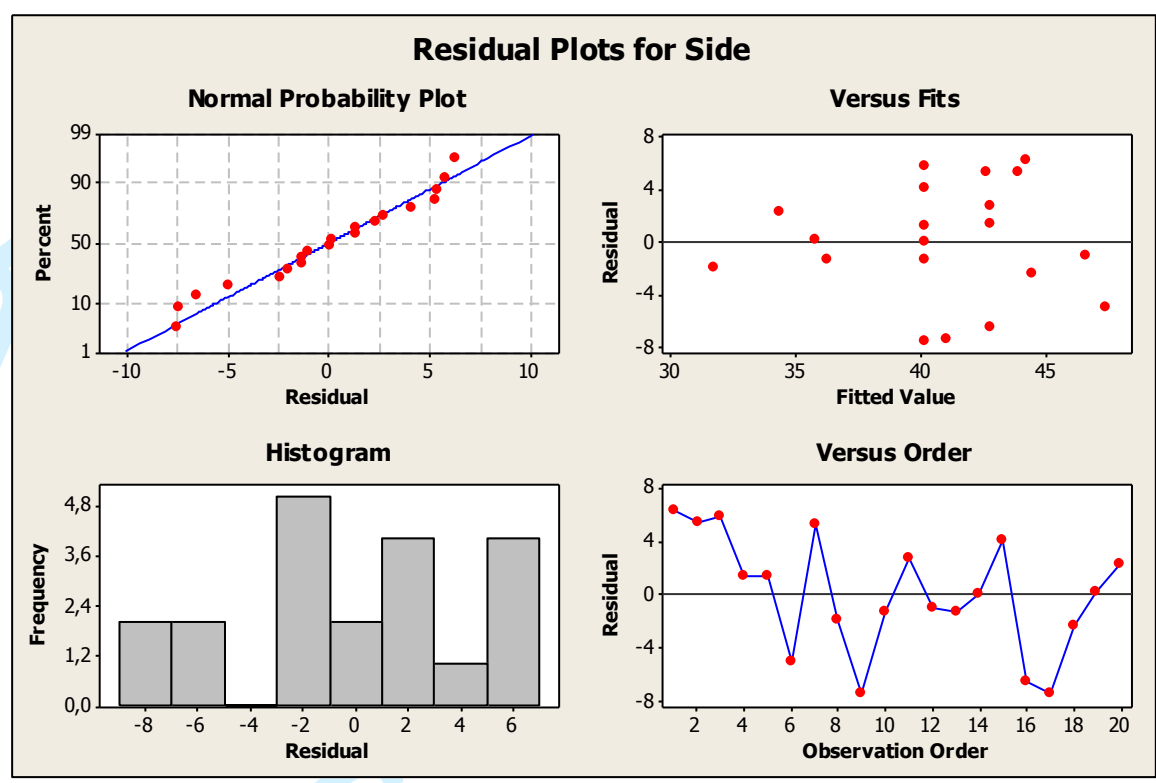

